\title{
Recent Advances in Hereditary Angioedema Self-Administration Treatment: Summary of an International Hereditary Angioedema Expert Meeting
}

\author{
Timothy J. Craig \\ College of Medicine, Penn State University, Hershey Medical Center, Hershey, Pa., USA
}

\section{Overall Perspective}

With more products becoming licensed for self-administration treatment of hereditary angioedema (HAE) [Berinert ( $\mathrm{C} 1$ esterase inhibitor), Firazyr (icatibant) and Cinryze (C1 esterase inhibitor)] healthcare professionals are increasingly offering this option to their patients. To discuss issues relating to self-administration therapy of HAE, a group of experts from Europe, the USA and Canada met to share their experiences and to discuss how to encourage more patients to self-administer.

HAE is a rare autosomal dominant condition, with an estimated prevalence of between 1:10,000 and 1:50,000, which affects all ethnicities and age groups. Clinically, HAE is characterised by acute attacks of non-pitting, non-pruritic swelling of the skin and subcutaneous tissue and is potentially a life-threatening condition. To date, treatment approaches have included the management of acute attacks or prophylactic treatment. Recently, a number of therapies for self-administration have become licensed for use; however, self-administration has not been as widely adopted as one might have predicted.

This international HAE expert meeting, supported by an educational grant from CSL Behring, was held in Ge- neva, Switzerland, in June 2012. The aim of the meeting was to gain an insight into the current use of self-administration amongst patients from across Europe, the USA and Canada and to gain feedback on what needs to be done to encourage further use. This meeting enabled clinicians, nurses and a patient-expert to share their experience to date and to develop consensus of these experts in the field. The meeting highlighted differences between continents in the regulatory and legal frameworks for self-administration therapy and highlighted a need for further training resources for both healthcare teams and patients alike.

This supplement is divided into four papers which summarise the main points of consensus and areas that require further investigation to maximise the patient/ physician experience. It was created following the international HAE expert meeting to highlight the need for further encouragement for the use of self-administration in order to improve patients' quality of life and to highlight areas for improvement to aid the management of treatment for patients. In the first article of this supplement, Cicardi et al. [1] highlight the current guidelines and published material on the treatment of HAE with particular consideration to the use of self-administration. The guidelines indicate the importance of training and follow-up and that self-administration may lead to an im-

\section{KARGER}

E-Mail karger@karger.com

www.karger.com/iaa
(C) 2013 S. Karger AG, Basel

1018-2438/13/1615-0001\$38.00/0
Correspondence to: Dr. Timothy J. Craig

College of Medicine, Penn State University

Hershey Medical Center

Hershey, PA 17033 (USA)

E-Mail tcraig@hmc.psu.edu 
provement in patients' quality of life. In the second paper, by Caballero et al. [2], we report the feedback from a survey and participant experience with treating $\mathrm{C} 1$ esterase inhibitor deficiency. Data show a variety of experience throughout different clinics and that there are improvements that can be made to the current systems.

The practical aspects of self-administration are discussed in the third paper by Symons et al. [3], leading to the conclusions that patients are quick to learn the necessary skills, but further support such as a helpline would be a welcome addition to available resources. The final paper, by Boysen et al. [4], identifies some of the challenges faced by patients and that HAE awareness needs to be increased to improve patient diagnosis and treatment.

It is vital in today's changing medical field to take note of real-world clinical experience because it highlights potential areas for maximising further resources, develop- ment of best practice, removal of barriers, improved patient compliance and communication about therapy. We hope that information presented in this supplement will foster awareness of the benefits of self-administration and will raise awareness of HAE and its management.

I would like to express my thanks to all the participants of the international HAE expert meeting for their valuable contributions, and to CSL Behring for their support in the production of the supplement.

\section{Disclosure Statement}

Dr. Craig speaks for CSL Behring, ViroPharma, Shire and Dyax. He does research for Pharming, CSL Behring, ViroPharma, Shire and Dyax. He is a consultant for CSL Behring and Dyax and has received educational grants from Dyax, ViroPharma and CSL Behring.
References
1 Cicardi M, Craig TJ, Martinez-Saguer I, Hébert J, Longhurst HJ: Review of recent guidelines and consensus statements on hereditary angioedema therapy with focus on self-administration. Int Arch Allergy Immunol 2013;161(suppl 1):3-9.

2 Caballero T, Sala-Cunill A, Cancian M, Craig TJ, Neri S, Keith PK, Boccon-Gibod I, Bethune $\mathrm{C}$, Bork K: Current status of implementation of self-administration training in various regions of Europe, Canada and the USA in the management of hereditary angioedema. Int Arch Allergy Immunol 2013;161 (suppl 1):10-16.
- 3 Symons C, Rossi O, Magerl M, Andritschke K: Practical approach to self-administration of intravenous C1-INH concentrate: a nursing perspective. Int Arch Allergy Immunol 2013; 161(suppl 1):17-20.

-4 Boysen HB, Bouillet L, Aygören-Pürsün E: Challenges of $\mathrm{C} 1$-inhibitor concentrate selfadministration. Int Arch Allergy Immunol 2013;161(suppl 1):21-25. 